\title{
Using High-Pressure Torsion to Achieve Superplasticity in an AZ91 Magnesium Alloy
}

\author{
Roberto B. Figueiredo ${ }^{1, *}$ and Terence G. Langdon ${ }^{2,3}$ \\ 1 Department of Metallurgical and Materials Engineering, Universidade Federal de Minas Gerais, \\ Belo Horizonte, MG 31270-901, Brazil \\ 2 Materials Research Group, Department of Mechanical Engineering, University of Southampton, \\ Southampton SO17 1BJ, UK; T.G.Langdon@soton.ac.uk or langdon@usc.edu \\ 3 Departments of Aerospace and Mechanical Engineering and Materials Science, \\ University of Southern California, Los Angeles, CA 90089-1453, USA \\ * Correspondence: figueiredo@demet.ufmg.br; Tel.: +55-31-3409-1925
}

Received: 2 May 2020; Accepted: 19 May 2020; Published: 22 May 2020

\begin{abstract}
An AZ91 magnesium alloy (Mg-9\%, Al-1\% Zn) was processed by high-pressure torsion (HPT) after solution-heat treatment. Tensile tests were carried out at 423, 523, and $623 \mathrm{~K}$ in the strain rate range of $10^{-5}-10^{-1} \mathrm{~s}^{-1}$ to evaluate the occurrence of superplasticity. Results showed that HPT processing refined the grain structure in the alloy, and grain sizes smaller than $10 \mu \mathrm{m}$ were retained up to $623 \mathrm{~K}$. Superplastic elongations were observed at low strain rates at $423 \mathrm{~K}$ and at all strain rates at $523 \mathrm{~K}$. An examination of the experiment data showed good agreement with the theoretical prediction for grain-boundary sliding, the rate-controlling mechanism for superplasticity. Elongations in the range of 300-400\% were observed at $623 \mathrm{~K}$, attributed to a combination of grain-boundary-sliding and dislocation-climb mechanisms.
\end{abstract}

Keywords: creep; high-pressure torsion; magnesium; superplasticity

\section{Introduction}

Superplasticity refers to the ability of a polycrystalline material to undergo large stable deformation in tension and achieve high elongation prior to failure. Formally, it was defined as elongations larger than $400 \%$ and strain-rate sensitivity of $\sim 0.5$ [1]. It is now recognized that the deformation mechanism associated with superplasticity is grain-boundary sliding in which the grains slide over each other with little or no change in their overall shape [2]. In practice, sliding along grain boundaries is caused by the movement of grain-boundary dislocations that then pile up at obstacles such as triple junctions and activate slip in a neighboring grain as an accommodating mechanism [3]. This leads to a pile up of dislocations at the opposite grain boundary, and the rate of deformation is then controlled by the rate of climb of these dislocations at the head of the pile up. Two requirements for superplasticity are a fine-grained structure, with average grain sizes typically smaller than $\sim 10 \mu \mathrm{m}$, and a high homologous temperature, typically larger than $\sim 0.5$ of the absolute melting temperature [4].

Small grain sizes in the range of a few microns are usually obtained through conventional thermomechanical-processing operations such as extrusion and rolling. More recently, the development of severe-plastic-deformation (SPD) [5] techniques, such as equal-channel angular pressing (ECAP) [6] and high-pressure torsion [7], allowed the production of metallic materials with ultrafine $(<1 \mu \mathrm{m})$ or even nanostructured grains $(<100 \mathrm{~nm})$. This significant decrease in structural size, compared to conventional thermomechanical processing, allowed the introduction of superplastic behavior into a very wide range of different alloys, and affected the temperature and strain-rate range associated with the superplastic process. In practice, it is now recognized that superplastic behavior is observed at lower temperatures 
and/or faster strain rates when grain size is decreased. Moreover, it is also clear that a decrease in grain size may also increase the maximal elongations achieved under superplastic deformation.

Early reports showed that ECAP processing introduced superplastic properties in many different magnesium alloys, including Mg-0.6\% Zr [8], Mg-9\% Al [9], and commercial alloys AZ31 [10-12], AZ91 [13-17], and ZK60 [15,18-22]. It also led to the highest elongation reported to date in a superplastic magnesium alloy [23]. Despite the outstanding ability to develop superplasticity in magnesium alloys, the ECAP processing of these alloys is generally highly demanding. This is due to their limited formability and restricted slip systems that tend to prevent easy processing at ambient temperature, and invariably lead to cracking, inhomogeneities, and segmentation within the gauge section [24]. In practice, therefore, heating the dies and samples is time-consuming and limits the overall effectiveness of grain refinement.

By contrast, the high hydrostatic compressive stresses developed in high-pressure torsion (HPT) provide an opportunity for delaying or even effectively suppressing the advent of early sample failure [25-27]. A further advantage of HPT processing is the ability to apply severe plastic deformation in magnesium alloys at room temperature, and thereby achieve exceptionally fine grain structures. A recent review on the HPT processing of magnesium alloys [28] revealed that there are few reports concerning the development of superplasticity in these alloys. In addition, although the as-processed grain structures are finer in HPT-processed magnesium alloys, the inherent high density of crystalline defects may serve to reduce the overall thermal stability of these materials. As a consequence, grain growth may take place in the temperature range associated with superplasticity, and thus prevent the occurrence of high superplastic elongations. This deficiency may be critical if planning to use these alloys in industrial superplastic-forming operations [29].

The present paper was prepared with the objective of evaluating the high-temperature behavior of an AZ91 magnesium alloy processed by HPT, with special emphasis on the ranges of temperature and strain rates associated with the development of superplastic flow. As is demonstrated, it is feasible to use HPT processing to achieve excellent superplastic properties in the AZ91 alloy with elongations up to and exceeding $1000 \%$.

\section{Materials and Methods}

The material used in the present investigation was an AZ91 magnesium alloy (Mg-9\% Al-1\% Zn) provided by Rima (Bocaiuva/MG, Brazil) as a cast slab. A piece in the shape of a cylinder $10 \mathrm{~mm}$ diameter and $60 \mathrm{~mm}$ length was machined from the as-cast material and subjected to solution treatment at $693 \mathrm{~K}$ for $24 \mathrm{~h}$, followed by water quenching. Discs with thickness of $\sim 0.9 \mathrm{~mm}$ were cut from the solution-treated cylinder and ground to $\sim 0.85 \mathrm{~mm}$. HPT processing was carried out at room temperature using a quasiconstrained facility $[27,30]$. The rotation rate was $2 \mathrm{rpm}$, and discs were processed to 10 turns under an applied pressure of $6.0 \mathrm{GPa}$. A detailed characterization of the processed material is given elsewhere [31].

Miniature tensile specimens with $1 \mathrm{~mm}$ gauge length were cut from the processed discs using spark erosion. Tensile tests were carried out at temperatures of 423,523 , and $623 \mathrm{~K}$ using a furnace adapted to a universal testing machine. Samples were heated with the testing grips, and temperature homogenization was achieved by maintaining the testing temperature for $30 \mathrm{~min}$ before starting the test. Testing was carried out at a constant rate of cross-head displacement with initial strain rates in the range of $10^{-5}-10^{-1} \mathrm{~s}^{-1}$. The load and displacement data were converted into stress and strain. The elastic portions of the stress-strain curves were associated with the elastic modulus of magnesium to minimize the distortion of the testing machine and tensile grips. In order to estimate grain growth due to high-temperature exposure, the microstructures at the grip areas of the samples tested at the highest strain rates were examined using conventional metallographic techniques. These areas did not undergo straining during tensile testing, and exposure time was only slightly longer than for the samples subjected to testing. Therefore, grain structures in these areas were considered representative 
of the initial grain structures in the gauge area. Spatial grain sizes $d$ were determined using relationship $d=1.74 \times \bar{L}$, where $\bar{L}$ is mean linear intercept length [32].

\section{Results}

True stress vs. true strain curves obtained from tensile tests at different temperatures and strain rates are shown in Figure 1. Flow stresses decreased at lower testing strain rates and higher temperatures. All curves displayed a large initial portion in which stress increased with increasing strain. This strain-hardening behavior was observed earlier in a superplastic magnesium alloy, and attributed to grain growth during deformation [33]. The sample pulled in tension with an initial strain rate of $10^{-2} \mathrm{~s}^{-1}$ at $423 \mathrm{~K}$ failed without noticeable deformation, which suggested brittle behavior. Therefore, the curve associated with this condition was not included in Figure 1.

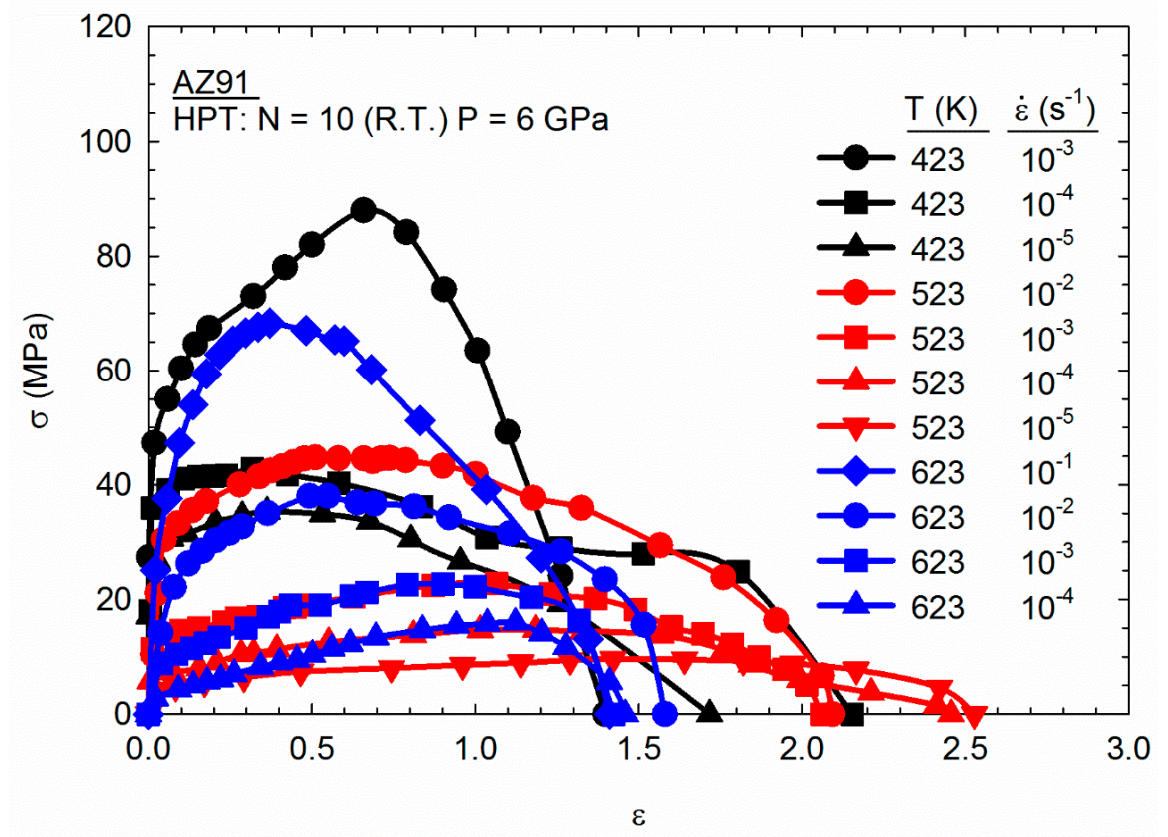

Figure 1. True stress vs. true strain curves obtained at different testing temperatures and strain rates.

Figure 2 shows the appearance of specimens pulled to failure at different temperatures and strain rates with an untested specimen shown at the top for comparison purposes. The final elongations to failure are listed to the right of each sample. Superplastic elongations, defined as elongations $>400 \%$, were observed at $423 \mathrm{~K}$ at strain rates of $10^{-4} \mathrm{~s}^{-1}$ and slower, and at all strain rates tested at $523 \mathrm{~K}$. The report of superplasticity at $423 \mathrm{~K}$ was considered representative of low-temperature superplasticity because this temperature was lower than $0.5 T_{m}$, where $T_{m}$ is the absolute melting temperature. Superplastic elongation was observed at $10^{-2} \mathrm{~s}^{-1}$ at $523 \mathrm{~K}$, which was considered representative of high-strain-rate superplasticity [34]. Although superplastic elongations were not observed at $10^{-3} \mathrm{~s}^{-1}$ at the lower testing temperature of $423 \mathrm{~K}$ and at the highest testing temperature of $623 \mathrm{~K}$, the final elongations were in the range of $\sim 300-400 \%$ for these conditions, which is exceptionally high for magnesium alloys. Specimens pulled under superplastic conditions exhibited no evidence of any localized necking within the gauge area, which is consistent with expectations for true superplastic flow [35]. 


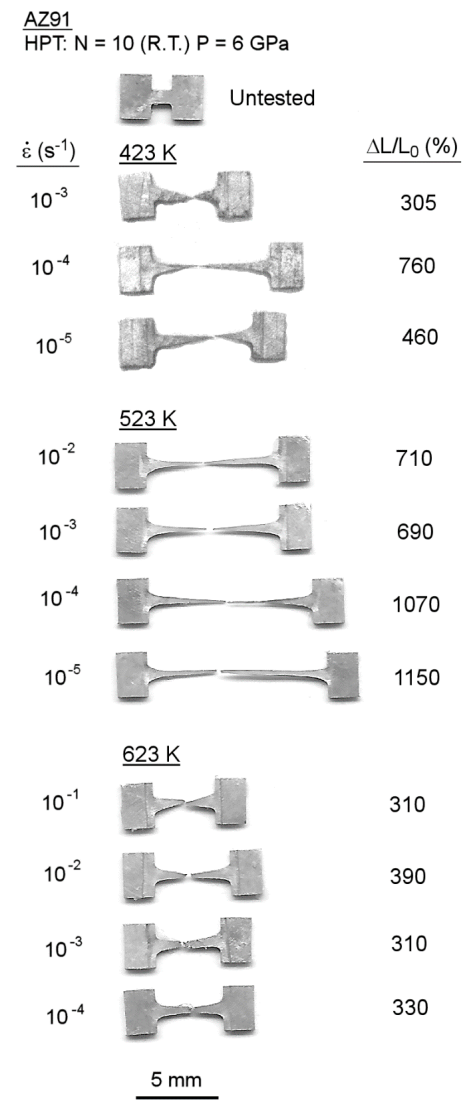

Figure 2. Appearance of tensile specimens pulled to failure at different temperatures and strain rates.

The grain structures observed in the grip area are shown in Figure 3 for samples heated to the testing temperatures of (a) 423, (b) 523, and (c) $623 \mathrm{~K}$, respectively. The image at $623 \mathrm{~K}$ was taken at a lower magnification. Average grain sizes were recorded as $\sim 1.3, \sim 3.3$, and $\sim 9.6 \mu \mathrm{m}$, respectively. This showed that the grain structure was not stable in this temperature range but all grain sizes remained within the conventional upper limit of $\sim 10 \mu \mathrm{m}$ for superplasticity [4]. An earlier report showed that the grain size obtained in a similar alloy processed by HPT using similar processing parameters was $\sim 100 \mathrm{~nm}$ [31]. Therefore, significant grain growth took place even at the lowest testing temperature of $423 \mathrm{~K}$. The highest elongations providing evidence for high-strain-rate superplasticity were observed at 523 K. Precipitation of second-phase particles was observed at this temperature. Many grain boundaries appeared to be decorated with second-phase particles at $523 \mathrm{~K}$. The formation of a $\mathrm{Zn}$-rich film along the grain boundaries of aluminum was associated with improved strain-rate sensitivity [36]. These precipitates might aid in impeding grain growth. Therefore, the excellent superplastic behavior observed at $523 \mathrm{~K}$ can be associated, in part, with the precipitation of second-phase particles along grain boundaries. 

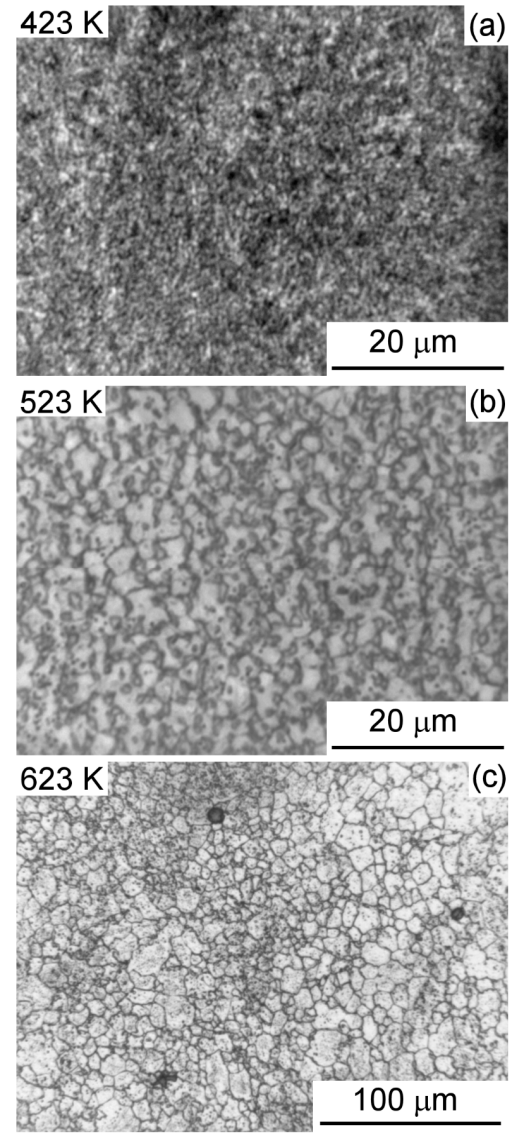

Figure 3. Grain structure at grip area in samples heated to (a) $423 \mathrm{~K}$, (b) $523 \mathrm{~K}$, and (c) $623 \mathrm{~K}$.

\section{Discussion}

The present results showed that grain sizes obtained in the AZ91 alloy after HPT processing followed by heating to the temperature range of 423 to $623 \mathrm{~K}$ were smaller than the limiting grain sizes for superplasticity $(\sim 10 \mu \mathrm{m})$. In practice, superplastic elongations up to and over $1000 \%$ were achieved in these experiments. Analysis of deformation behavior showed a significant difference between the fine- and coarse-grained AZ91 alloys in this temperature range.

Figure 4 shows flow-stress plots as a function of strain rate observed in the present experiments and in experiment data collected from published reports [14,37-41] for testing temperatures of (a) 423, (b) 523, and (c) $623 \mathrm{~K}$. Grain sizes reported in various experiments were also recorded. It was clearly observed that the present data and other data from the fine-grained AZ91 alloy exhibited lower flow stresses and/or faster strain rates than those of their coarse-grained counterparts. For example, the creep testing of cast AZ91 alloy [37,39] resulted in strain rates more than three orders of magnitude slower than those observed in the present experiments for similar levels of flow stress at $423 \mathrm{~K}$. The present data agreed fairly well with other reports of high-temperature testing of AZ91 processed by ECAP [14] and HPT [38] in which the range of grain sizes was similar. A coarse-grained ( $\sim 55 \mu \mathrm{m})$ AZ91 alloy [40] exhibited much larger flow stresses at 523 and $623 \mathrm{~K}$ within a similar strain-rate range than flow stresses observed in the present experiments. Analysis showed that the deformation mechanism operating under these conditions in the coarse-grained alloy was dislocation climb. 

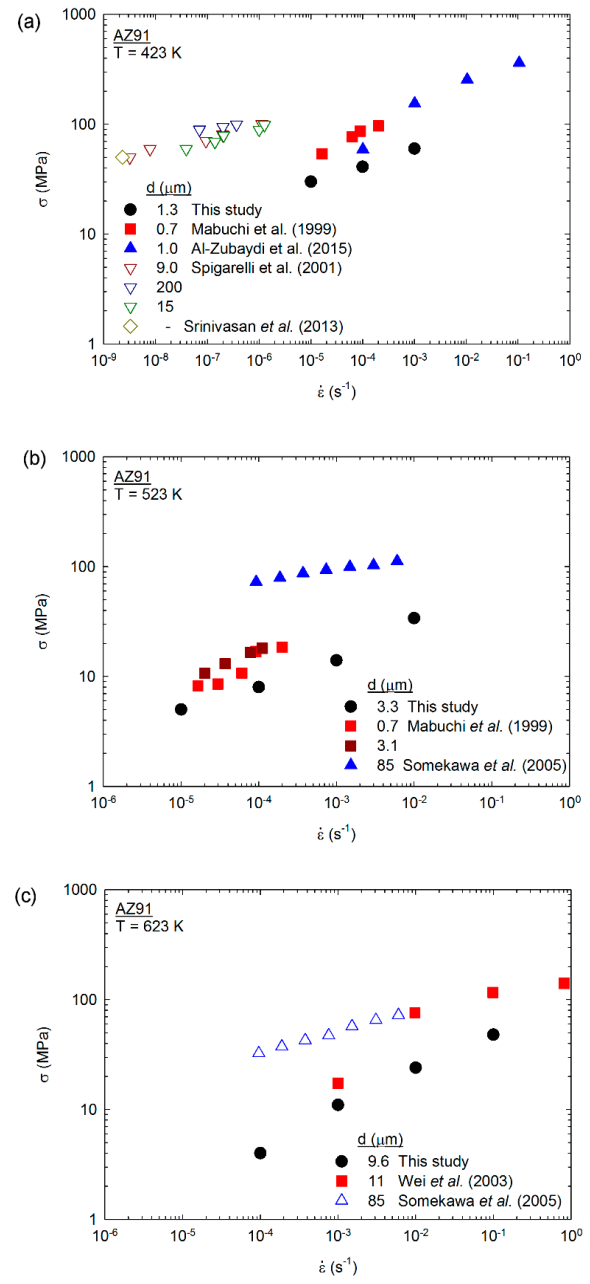

Figure 4. Plots of stress vs. strain rate for AZ91 alloy with different grain sizes and tested at (a) $423 \mathrm{~K}$, (b) $523 \mathrm{~K}$, and (c) $623 \mathrm{~K}$. Data from the literature [14,37-41] were also included.

The deformation mechanism associated with superplasticity is grain-boundary sliding, and the strain rate for this mechanism is given by an equation of form

$$
\dot{\varepsilon}_{G B S}=5 \frac{\delta D_{g b} G}{K T}\left(\frac{b}{d}\right)^{2}\left(\frac{\sigma}{G}\right)^{2}
$$

where $\delta$ is the grain-boundary width (considered to be $2 b$ ), $b$ is the Burgers vector modulus, $D_{g b}$ is the grain-boundary diffusion coefficient, $G$ is the shear modulus, $k$ is Boltzmann's constant, $T$ is the absolute temperature, and $\sigma$ is flow stress.

Previous investigations [11,42] showed that this equation predicted well the behavior of the AZ31 magnesium alloy in conditions where superplasticity was observed. In order to evaluate whether the equation also reasonably predicted the behavior of the AZ91 alloy, the present data and other results from the literature reporting superplasticity in this alloy $[14,38,41,43]$ were compared to the theoretical prediction in Figure 5, where strain rate was normalized by the effect of grain size and temperature, and plotted as a function of the stress normalized by the shear modulus. It is apparent that data in Figure 5, which correspond to various processing techniques including HPT [38], ECAP, and ECAP + Annealing [14], extrusion [43] and rolling [41], showed good agreement with the theoretical prediction and, therefore, confirmed the mechanism of grain-boundary sliding as the rate-controlling mechanism for the AZ91 alloy. The only set of results that tended to fall below the prediction were associated with the material processed by ECAP. However, an as-processed grain size of $\sim 0.7 \mu \mathrm{m}$ was reported 
for this condition, and the subsequent occurrence of grain growth before high-temperature testing was not considered. Therefore, it is reasonable that the datum points were not fully consistent with the predictions.

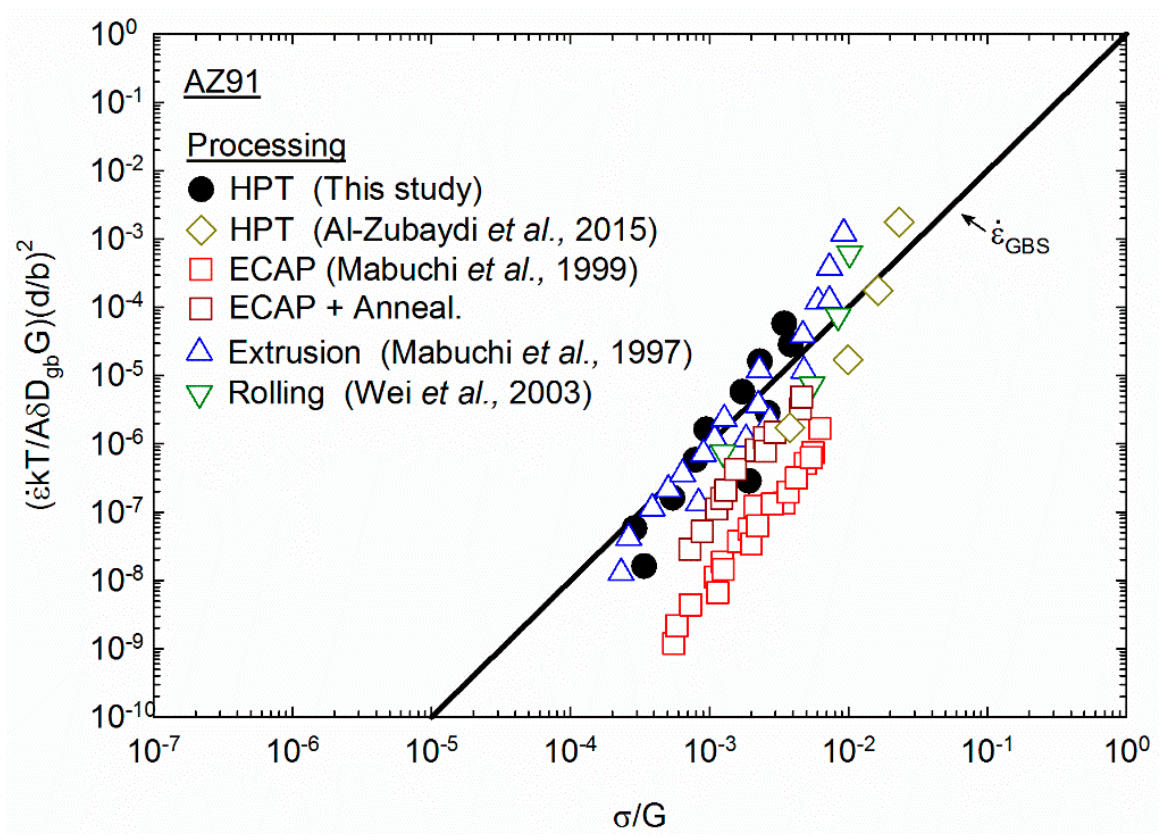

Figure 5. Strain rate normalized by effect of temperature and grain size, and plotted as function of stress normalized by shear modulus. Data from the literature $[14,38,41,43]$ were also included.

Different thermomechanical-processing operations introduced superplasticity in the AZ91 alloy. In Figure 5, data were collected from various processing methods, but the largest elongations were associated with processing by SPD. Thus, maximal elongations of 425\% [43] and 455\% [41] were reported after extrusion and rolling, respectively, whereas elongations of 956\% [14] and 1308\% [38] were reported after ECAP and HPT, respectively. The present results confirmed that SPD was the optimal processing technique to introduce superplasticity in this alloy, as elongations over $1000 \%$ were observed at $523 \mathrm{~K}$ at strain rates of $10^{-5} \mathrm{~s}^{-1}$ and $10^{-4} \mathrm{~s}^{-1}$. Elongations over $400 \%$, which is considered a limiting threshold for superplasticity, were also not reported at temperatures below $0.5 T_{m}$ or at strain rates of $10^{-2} \mathrm{~s}^{-1}$ or faster after extrusion or rolling. However, low-temperature superplasticity at $T=423 \mathrm{~K}$ was obtained in the present experiments in material processed by ECAP [14] and HPT [38]. High-strain-rate superplasticity was observed in the present experiments and reported only after HPT processing [38].

Finally, samples tested at $10^{-3} \mathrm{~s}^{-1}$ at $423 \mathrm{~K}$ and at all strain rates at $623 \mathrm{~K}$ displayed elongations in the range of $300-400 \%$. Although these elongations were below the conventional limiting threshold for superplasticity, they were much larger than elongations expected for coarse-grained material. Stressand strain-rate data observed in these conditions agreed well with the prediction for grain-boundary sliding. A recent report outlined analysis of the creep-deformation behavior of the fine-grained AZ31 alloy, and developed deformation-mechanism maps for this alloy [44]. It was shown that there is a region between the mechanisms of grain-boundary sliding and climb where both mechanisms appear to operate. The reason for this overlap was suggested to be the formation of subgrain structures within grains at large stresses that affect the operation of grain-boundary sliding. Thus, elongations between $300 \%$ and $400 \%$ observed in the present experiments were attributed to a combination of both grain-boundary-sliding and conventional dislocation-climb mechanisms. The combination of these deformation mechanisms was observed experimentally in the AZ31 alloy [45]. Although the alloying content in the AZ31 alloy differed from that in the AZ91 used in the present experiments, 
it is reasonable to anticipate that this difference should have no significant effect on the operative creep mechanisms.

\section{Conclusions}

(1) An AZ91 alloy was processed by HPT and tested in tension in the temperature range of 423 to $623 \mathrm{~K}$. Superplastic elongations were observed, including evidence for low-temperature and high-strain-rate superplasticity.

(2) Grain refinement changed the deformation mechanism in the alloy, and experiment data agreed well with the theoretical predictions for the grain-boundary sliding mechanism.

(3) Severe plastic deformation through HPT introduced superplastic properties at lower temperatures and/or at faster strain rates, and produced higher elongations than those in samples prepared using conventional thermomechanical processing.

(4) Elongations between $300 \%$ and $400 \%$ were observed at temperatures of 423 and $623 \mathrm{~K}$, attributed to the occurrence of a combination of grain-boundary-sliding and dislocation-climb mechanisms.

Author Contributions: Conceptualization, R.B.F. and T.G.L.; methodology, R.B.F. and T.G.L.; writing-review and editing, R.B.F. and T.G.L.; All authors have read and agreed to the published version of the manuscript.

Funding: The authors acknowledge support from FAPEMIG, CNPq, and the European Research Council under ERC grant agreement no. 267464-SPDMETALS.

Conflicts of Interest: The authors declare no conflict of interest.

\section{References}

1. Kawasaki, M.; Figueiredo, R.B.; Langdon, T.G. The requirements for superplasticity with an emphasis on magnesium alloys. Adv. Eng. Mater. 2016, 18, 127-131. [CrossRef]

2. Langdon, T.G. An evaluation of the strain contributed by grain boundary sliding in superplasticity. Mater. Sci. Eng. A 1994, 174, 225-230. [CrossRef]

3. Langdon, T.G. A unified approach to grain boundary sliding in creep and superplasticity. Acta Metall. Mater. 1994, 42, 2437-2443. [CrossRef]

4. Langdon, T.G. The mechanical properties of superplastic materials. Metall. Trans. A 1982, 13, 689-701. [CrossRef]

5. Valiev, R.Z.; Islamgaliev, R.K.; Alexandrov, I.V. Bulk nanostructured materials from severe plastic deformation. Prog. Mater. Sci. 2000, 45, 103-187. [CrossRef]

6. Valiev, R.Z.; Langdon, T.G. Principles of equal-channel angular pressing as a processing tool for grain refinement. Prog. Mater. Sci. 2006, 51, 881-981. [CrossRef]

7. Zhilyaev, A.P.; Langdon, T.G. Using high-pressure torsion for metal processing: Fundamentals and applications. Prog. Mater. Sci. 2008, 53, 893-979. [CrossRef]

8. Horita, Z.; Matsubara, K.; Makii, K.; Langdon, T.G. A two-step processing route for achieving a superplastic forming capability in dilute magnesium alloys. Scr. Mater. 2002, 47, 255-260. [CrossRef]

9. Matsubara, K.; Miyahara, Y.; Horita, Z.; Langdon, T.G. Developing superplasticity in a magnesium alloy through a combination of extrusion and ECAP. Acta Mater. 2003, 51, 3073-3084. [CrossRef]

10. Lin, H.K.; Huang, J.C.; Langdon, T.G. Relationship between texture and low temperature superplasticity in an extruded AZ31 Mg alloy processed by ECAP. Mater. Sci. Eng. A 2005, 402, 250-257. [CrossRef]

11. Figueiredo, R.B.; Langdon, T.G. Developing superplasticity in a magnesium AZ31 alloy by ECAP. J. Mater. Sci. 2008, 43, 7366-7371. [CrossRef]

12. Lapovok, R.; Estrin, Y.; Popov, M.V.; Langdon, T.G. Enhanced superplasticity in a magnesium alloy processed by equal-channel angular pressing with a back-pressure. Adv. Eng. Mater. 2008, 10, 429-433. [CrossRef]

13. Mabuchi, M.; Iwasaki, H.; Yanase, K.; Higashi, K. Low temperature superplasticity in an AZ91 magnesium alloy processed by ECAE. Scr. Mater. 1997, 36, 681-686. [CrossRef]

14. Mabuchi, M.; Ameyama, K.; Iwasaki, H.; Higashi, K. Low temperature superplasticity of AZ91 magnesium alloy with non-equilibrium grain boundaries. Acta Mater. 1999, 47, 2047-2057. [CrossRef] 
15. Chuvil'deev, V.N.; Nieh, T.G.; Gryaznov, M.Y.; Sysoev, A.N.; Kopylov, V.I. Low-temperature superplasticity and internal friction in microcrystalline Mg alloys processed by ECAP. Scr. Mater. 2004, 50, 861-865. [CrossRef]

16. Mabuchi, M.; Iwasaki, H.; Higashi, K. Low temperature superplasticity of magnesium alloys processed by ECAE. Mater. Sci. Forum 1996, 243-245, 547-552. [CrossRef]

17. Mabuchi, M.; Nakamura, M.; Ameyama, K.; Iwasaki, H.; Higashi, K. Superplastic behavior of magnesium alloy processed by ECAE. Mater. Sci. Forum 1999, 304-306, 67-72. [CrossRef]

18. Watanabe, H.; Mukai, T.; Ishikawa, K.; Higashi, K. Low temperature superplasticity of a fine-grained ZK60 magnesium alloy processed by equal-channel-angular extrusion. Scr. Mater. 2002, 46, 851-856. [CrossRef]

19. Watanabe, H.; Mukai, T.; Ishikawa, K.; Higashi, K. Superplastic behavior of an ECAE processed ZK60 magnesium alloy. Mater. Sci. Forum 2003, 419-422, 557-564. [CrossRef]

20. Lapovok, R.; Cottam, R.; Thomson, P.F.; Estrin, Y. Extraordinary superplastic ductility of magnesium alloy ZK60. J. Mater. Res. 2005, 20, 1375-1378. [CrossRef]

21. Figueiredo, R.B.; Langdon, T.G. The development of superplastic ductilities and microstructural homogeneity in a magnesium ZK60 alloy processed by ECAP. Mater. Sci. Eng. A 2006, 430, 151-156. [CrossRef]

22. Figueiredo, R.B.; Langdon, T.G. Strategies for achieving high strain rate superplasticity in magnesium alloys processed by equal-channel angular pressing. Scr. Mater. 2009, 61, 84-87. [CrossRef]

23. Figueiredo, R.B.; Langdon, T.G. Record superplastic ductility in a magnesium alloy processed by equal-channel angular pressing. Adv. Eng. Mater. 2008, 10,37-40. [CrossRef]

24. Cetlin, P.R.; Aguilar, M.T.P.; Figueiredo, R.B.; Langdon, T.G. Avoiding cracks and inhomogeneities in billets processed by ECAP. J. Mater. Sci. 2010, 45, 4561-4570. [CrossRef]

25. Pereira, P.H.R.; Figueiredo, R.B. Finite element modelling of high-pressure torsion: An overview. Mater. Trans. 2019, 60, 1139-1150. [CrossRef]

26. Figueiredo, R.B.; Aguilar, M.T.P.; Cetlin, P.R.; Langdon, T.G. Analysis of plastic flow during high-pressure torsion. J. Mater. Sci. 2012, 47, 7807-7814. [CrossRef]

27. Figueiredo, R.B.; Cetlin, P.R.; Langdon, T.G. Using finite element modeling to examine the flow processes in quasi-constrained high-pressure torsion. Mater. Sci. Eng. A 2011, 528, 8198-8204. [CrossRef]

28. Figueiredo, R.B.; Langdon, T.G. Processing magnesium and its alloys by high-pressure torsion: An overview. Adv. Eng. Mater. 2019, 21, 1801039. [CrossRef]

29. Barnes, A.J. Superplastic forming 40 years and still growing. J. Mater. Eng. Perform. 2007, 16, 440-454. [CrossRef]

30. Figueiredo, R.B.; Pereira, P.H.R.; Aguilar, M.T.P.; Cetlin, P.R.; Langdon, T.G. Using finite element modeling to examine the temperature distribution in quasi-constrained high-pressure torsion. Acta Mater. 2012, 60, 3190-3198. [CrossRef]

31. Silva, C.L.P.; Soares, R.B.; Pereira, P.H.R.; Figueiredo, R.B.; Lins, V.F.C.; Langdon, T.G. The effect of high-pressure torsion on microstructure, hardness and corrosion behavior for pure magnesium and different magnesium alloys. Adv. Eng. Mater. 2019, 21, 1801081. [CrossRef]

32. Mohamed, F.A.; Langdon, T.G. Creep at low stress levels in the superplastic Zn-22\% Al eutectoid. Acta Metall. 1975, 23, 117-124. [CrossRef]

33. Figueiredo, R.B.; Langdon, T.G. Influence of number of passes in ECAP on superplastic behavior in a magnesium alloy. Mater. Sci. Forum 2008, 584-586, 170-175. [CrossRef]

34. Higashi, K.; Mabuchi, M.; Langdon, T.G. High-strain-rate superplasticity in metallic materials and the potential for ceramic materials. ISIJ Int. 1996, 36, 1423-1438. [CrossRef]

35. Langdon, T.G. Fracture processes in superplastic flow. Met. Sci. 1982, 16, 175-183. [CrossRef]

36. Chinh, N.Q.; Valiev, R.Z.; Sauvage, X.; Varga, G.; Havancsák, K.; Kawasaki, M.; Straumal, B.B.; Langdon, T.G. Grain boundary phenomena in an ultrafine-grained Al-Zn alloy with improved mechanical behavior for micro-devices. Adv. Eng. Mater. 2014, 16, 1000-1009. [CrossRef]

37. Spigarelli, S.; Regev, M.; Evangelista, E.; Rosen, A. Review of creep behaviour of AZ91 magnesium alloy produced by different technologies. Mater. Sci. Technol. 2001, 17, 627-638. [CrossRef]

38. Al-Zubaydi, A.S.J.; Zhilyaev, A.P.; Wang, S.C.; Reed, P.A.S. Superplastic behaviour of AZ91 magnesium alloy processed by high-pressure torsion. Mater. Sci. Eng. A 2015, 637, 1-11. [CrossRef] 
39. Srinivasan, A.; Ajithkumar, K.K.; Swaminathan, J.; Pillai, U.T.S.; Pai, B.C. Creep Behavior of AZ91 Magnesium Alloy. In Proceedings of the 6th International Conference on Creep, Fatigue and Creep-Fatigue Interaction, Kalpakkam, India, 22-25 January 2012; Chetal, S.C., Jayakumar, T., Sandhya, R., Laha, K., Mathew, M.D., Eds.; Volume 55, pp. 109-113.

40. Somekawa, H.; Hirai, K.; Watanabe, H.; Takigawa, Y.; Higashi, K. Dislocation creep behavior in $\mathrm{Mg}-\mathrm{Al}-\mathrm{Zn}$ alloys. Mater. Sci. Eng. A 2005, 407, 53-61. [CrossRef]

41. Wei, Y.H.; Wang, Q.D.; Zhu, Y.P.; Zhou, H.T.; Ding, W.J.; Chino, Y.; Mabuchi, M. Superplasticity and grain boundary sliding in rolled AZ91 magnesium alloy at high strain rates. Mater. Sci. Eng. A 2003, 360, 107-115. [CrossRef]

42. Figueiredo, R.B.; Langdon, T.G. Evaluating the superplastic flow of a magnesium AZ31 alloy processed by equal-channel angular pressing. Metall. Mater. Trans. A 2014, 45, 3197-3204. [CrossRef]

43. Mabuchi, M.; Asahina, T.; Iwasaki, H.; Higashi, K. Experimental investigation of superplastic behaviour in magnesium alloys. Mater. Sci. Technol. 1997, 13, 825-831. [CrossRef]

44. Figueiredo, R.B.; Langdon, T.G. Analysis of the creep behavior of fine-grained AZ31 magnesium alloy. Mater. Sci. Eng. A 2020, 787, 139489. [CrossRef]

45. Dessolier, T.; Lhuissier, P.; Roussel-Dherbey, F.; Charlot, F.; Josserond, C.; Blandin, J.-J.; Martin, G. Effect of temperature on deformation mechanisms of AZ31 Mg-alloy under tensile loading. Mater. Sci. Eng. A 2020, 775, 138957. [CrossRef]

(C) 2020 by the authors. Licensee MDPI, Basel, Switzerland. This article is an open access article distributed under the terms and conditions of the Creative Commons Attribution (CC BY) license (http://creativecommons.org/licenses/by/4.0/). 